ORIGINAL ARTICLE

\title{
Non-neoplastic granulosa cells within ovarian vascular channels: a rare potential diagnostic piffall
}

\author{
W G McCluggage, R H Young
}

See end of article for authors' affiliations

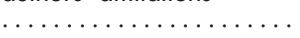

Correspondence to: Dr W G McCluggage, Department of Pathology, Royal Group of Hospitals Trust, Grosvenor Road Belfast BT1 2 6BL, Northern Ireland, UK: glenn. mccluggage@bll.n-i.nhs.uk

Accepted for publication 10 July 2003

\begin{abstract}
Aims: To describe six cases seen in consultation in which artefactual vascular involvement within the ovary by benign granulosa cells caused diagnostic confusion.

Methods/Results: In five cases, the initial favoured diagnoses of the submitting pathologists were metastatic carcinoma (three cases) and immature neural elements within a teratoma (two cases). In two cases, the ovary contained a benign cystic teratoma (one with struma ovarii), in two cases endometriosis, in one case follicular cysts, and in the other no pathological lesion was present. In all cases, several small ovarian vascular channels contained cohesive groups of cells with mildly atypical nuclei and cytoplasm, which varied from scant to abundant and eosinophilic. In four cases, mitotic figures were identified. The cells were morphologically consistent with benign granulosa cells and were associated in four cases with a nearby follicle lined by similar cells. There was no evidence of a mass lesion, grossly or histologically, to suggest a granulosa cell tumour. The nature of the cells was confirmed using immunohistochemistry for $\alpha$ inhibin and calretinin in one case.

Conclusions: This phenomenon is probably an artefact secondary to surgical trauma or sectioning within the laboratory; alternatively, it could be related to ovulation. It is important that this benign process is not misinterpreted as cancer, either primary or metastatic, which may prompt inappropriate treatment or investigations that are not needed.
\end{abstract}

G ranulosa cells are cells of sex cord derivation, which line developing follicles and follicular cysts within the ovary. Morphologically, granulosa cells are characterised by central bland or mildly atypical hyperchromatic nuclei. In the developing follicle, mitotic activity may be conspicuous. In this report, we describe a series of cases in which benign granulosa cells were present within ovarian vascular channels and typically led the original pathologist to consider a tumour as the explanation. Although vascular invasion by benign granulosa cells is described in some books, ${ }^{12}$ we are aware of only a single case report of this phenomenon that has been published in a clinical journal. ${ }^{3}$

\section{MATERIALS AND METHODS}

Four of the cases were identified from the consultation files of Dr R E Scully and two were seen in consultation by the authors. Specimens had been fixed in formalin and routinely processed in paraffin wax. In four cases, selected immunohistochemistry as detailed below was performed according to standard protocols. The number of slides showing the phenomenon of artefactual vascular invasion ranged from one to four. It was not possible to ascertain whether the involved vessels were lymphatic vessels or blood vessels, and we use the term "vascular" as a generic term to describe both.

\section{RESULTS}

Table 1 shows patient details, accompanying pathological findings, and the referral diagnoses. All patients were premenopausal. In case 6 , there was a history of resection of a cervical squamous carcinoma three years earlier.

In all cases, several small ovarian vascular channels contained cohesive groups of mildly atypical cells with an epithelioid appearance (fig 1). The number of vascular channels containing granulosa cells ranged from one to eight. Nuclei were round to ovoid, hyperchromatic, and nuclear grooves were not identified. In three cases, the cells had an appreciable amount of eosinophilic cytoplasm (fig 2), whereas in the three other cases the amount of cytoplasm was scant (fig 3). In these last three cases, the nuclei sometimes appeared crushed, resembling small cell carcinoma (fig 3). In four cases, mitotic figures were identified (fig 4). In three cases, occasional cohesive groups of cells appeared to lie within the ovarian stroma (fig 5). In four cases, there was a nearby follicle lined by granulosa cells (fig 6). In these cases, the follicle became more conspicuous on levelling the block.

Using immunohistochemistry, the cells within the vascular channels in case 1 were positive for $\alpha$ inhibin (fig 7) and calretinin (fig 8), but negative for epithelial membrane antigen (EMA) and cytokeratin. In case 2, the cells were positive for cytokeratin (punctate cytoplasmic staining) and negative for chromogranin, leucocyte common antigen (LCA), and carcinoembryonic antigen. In case 3 , the cells were positive for vimentin and negative for carcinoembryonic antigen and cytokeratin. The cells in case 4 were positive for vimentin and cytokeratin and negative for LCA. Immunohistochemistry was not performed in cases 5 and 6 because a confident diagnosis was rendered on routine stains.

\section{DISCUSSION}

One of the main areas that makes diagnostic surgical pathology an art as much as a science is the interpretation of cases in which changes seen under the microscope are artefactual. In some cases, such artefacts may cause a benign lesion to be misdiagnosed as malignant. ${ }^{45}$ The presence of mildly atypical granulosa cells within ovarian vascular channels and stroma in the cases we have described resulted in consideration of a malignant lesion. In four cases, the

Abbreviations: EMA, epithelial membrane antigen; LCA, leucocyte common antigen 
Table 1 Patient details, pathological findings, and referral diagnoses

\begin{tabular}{|c|c|c|c|c|c|}
\hline Case & Age & Operation & $\begin{array}{l}\text { Other pathology in ovary with } \\
\text { granulosa cells in lymphovascular } \\
\text { channels }\end{array}$ & Other pathology & Referral diagnosis \\
\hline Case 1 & 47 & $\mathrm{TAH}+\mathrm{BSO}$ & None & Uterine leiomyomas & Not applicable \\
\hline Case 2 & 46 & $\mathrm{TAH}+\mathrm{BSO}$ & Endometriosis & $\begin{array}{l}\text { Endometriosis other ovary; } \\
\text { adenomyosis }\end{array}$ & $\begin{array}{l}\text { ?Metastatic adenocarcinoma, probably } \\
\text { from breast; ?carcinoid }\end{array}$ \\
\hline Case 3 & 44 & $\mathrm{TAH}+\mathrm{BSO}$ & Endometriosis & Endometriosis other ovary & $\begin{array}{l}\text { ?Metastatic carcinoma breast; ?carcinoid; } \\
\text { ?metastatic malignant melanoma; } \\
\text { ?mesothelial cells }\end{array}$ \\
\hline Case 4 & 37 & LSO & Benign cystic teratoma (struma ovarii) & & ?lmmature neural elements \\
\hline Case 5 & 22 & RSO & Benign cystic teratoma & & ?lmmature neural elements \\
\hline Case 6 & 31 & BSO & Follicular cysts & $\begin{array}{l}\text { Follicular cysts other ovary; squamous } \\
\text { cell carcinoma cervix } 3 \text { years earlier }\end{array}$ & ?Metastatic squamous carcinoma \\
\hline
\end{tabular}

BSO, bilateral salpingo-oophorectomy; LSO, left salpingo-oophorectomy; RSO, right salpingo-oophorectomy; TAH+BSO, total abdominal hysterectomy and bilateral salpingo-oophorectomy.

presence of a nearby follicle lined by granulosa cells, often seen more clearly on levelling the block, was a clue to the nature of the cells. Because mitotic activity can be conspicuous in developing follicles, it is not surprising that in four of our cases mitoses were identified within the cells involving vascular channels.

In three cases, the preferred referral diagnosis was metastatic carcinoma, and in some cases further investigations were undertaken to exclude a carcinoma. However, it would be extremely unusual for a metastatic lesion to present in the ovary with only vascular involvement. When a metastasis to the ovary presents in an occult manner, there is usually a mass lesion grossly, or at least a mass lesion of microscopic dimension effacing a small part of the parenchyma, as opposed to entirely vascular invasion. In two cases, the presence of cells with abundant eosinophilic cytoplasm, presumably representing cytoplasmic luteinisation, was reminiscent of metastatic breast carcinoma, whereas in another case a diagnosis of metastatic squamous carcinoma was considered because of the history of resection of a cervical squamous carcinoma three years earlier. The crushed nuclei and scant cytoplasm in some cases were reminiscent of a small cell carcinoma or a lymphoma, and other diagnoses entertained included metastatic malignant melanoma and carcinoid tumour.

Negative staining with neuroendocrine markers would help to exclude a small cell carcinoma, although some small cell carcinomas are negative. The cohesive nature of the cells argue against a lymphoma, and negative staining for LCA helps to exclude this diagnosis, because most morphological subtypes of lymphoma are positive. In excluding malignant melanoma and carcinoid tumour, melanocytic and

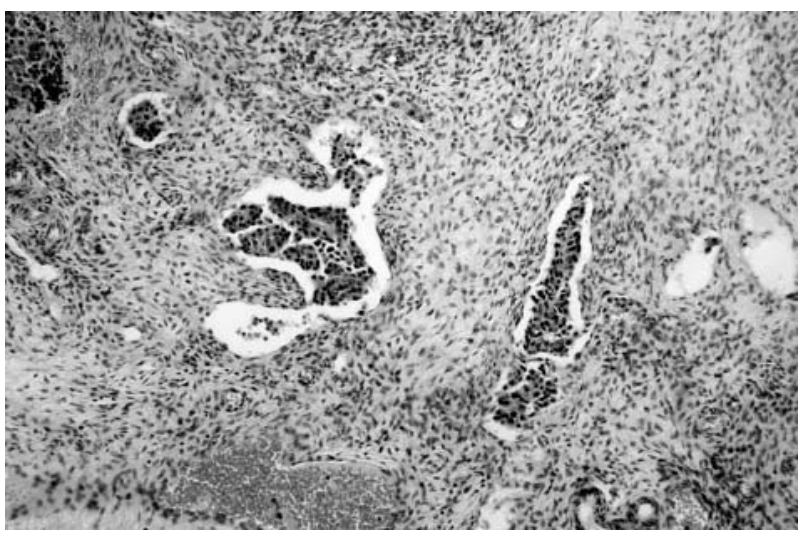

Figure 1 Cohesive cells with an epithelioid appearance within ovarian vascular channels. neuroendocrine markers, respectively, would be of value. Benign mesothelial cells were also suggested in the differential diagnosis by the referring pathologist in one case. In excluding mesothelial cells, immunhistochemistry with antibodies directed against mesothelial markers may be of value, although it should be noted that calretinin is commonly positive in both mesothelial and sex cord stromal cells. ${ }^{67}$ In this regard, other mesothelial markers such as HBMEl, thrombomodulin, and cytokeratin 5/6 may be of value.

In two cases, the ovary containing granulosa cells within vascular channels also harboured a benign cystic teratoma. This resulted in consideration of immature neural elements and an immature teratoma. However, the presence of immature neural elements within vascular channels would be unusual, and there was no background fibrillary material or rosette formation, features that are often seen in immature neural elements.

\section{"Once it is realised that the cells within vascular channels are probably granulosa cells confirmation is easy using immunohistochemistry"}

Another entity to be considered in the differential diagnosis is a granulosa cell tumour with vascular invasion. In this instance, immunohistochemistry would be of no value, but a granulosa cell tumour is easily excluded by the absence of a mass lesion grossly or histologically. In addition, the nuclei of granulosa cell tumours are usually pale and have easily identifiable nuclear grooves, in contrast to the hyperchromatic non-grooved nuclei of benign granulosa

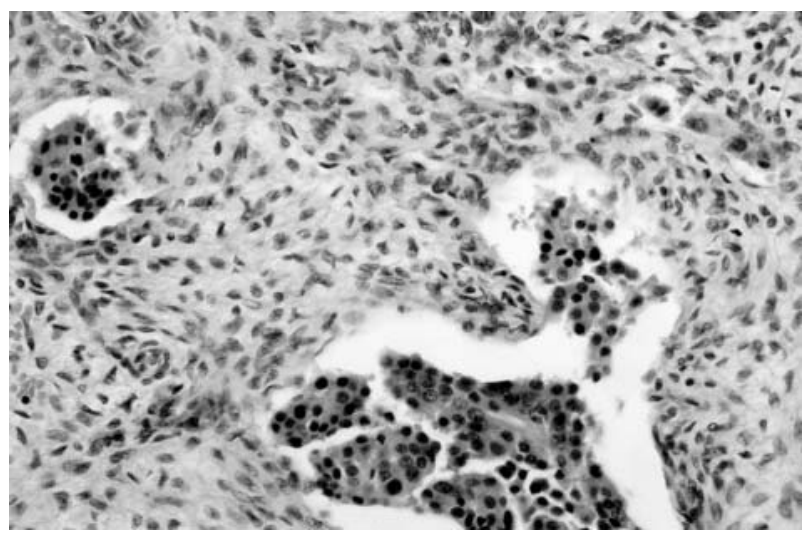

Figure 2 Cohesive cells with abundant eosinophilic cytoplasm within vascular channels. 


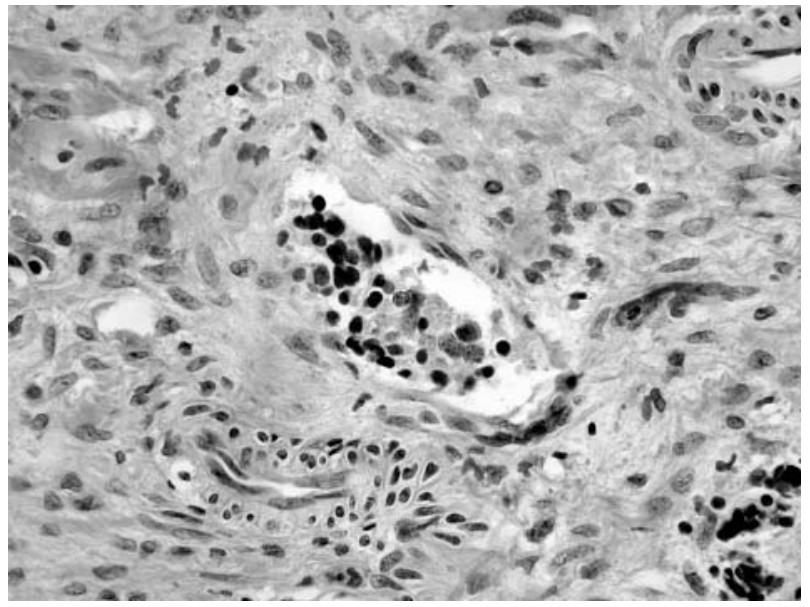

Figure 3 Group of cells with crushed nuclei and scant cytoplasm within vascular channels.

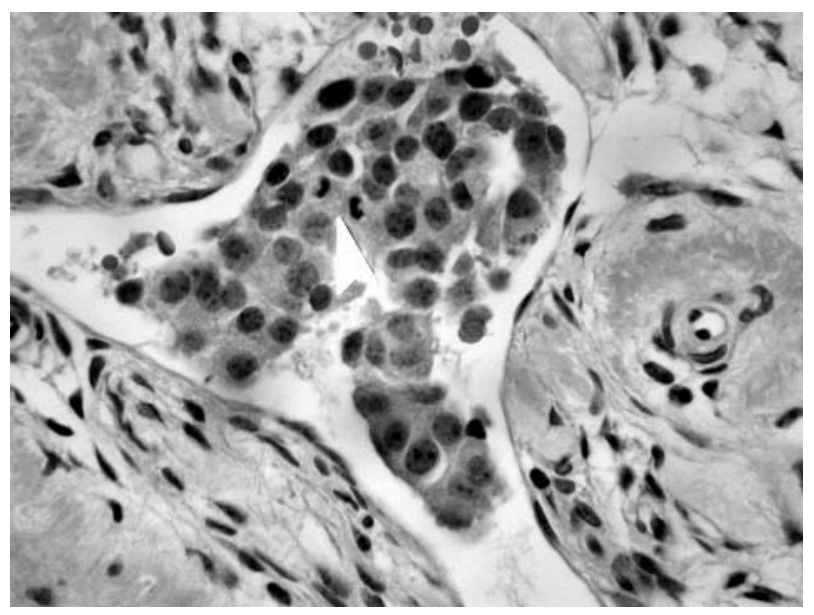

Figure 4 Occasional mitotic figures (arrow) in granulosa cells.

cells. Furthermore, prominent vascular invasion is unusual in granulosa cell tumours.

Once it is realised that the cells within vascular channels are probably granulosa cells confirmation is easy using

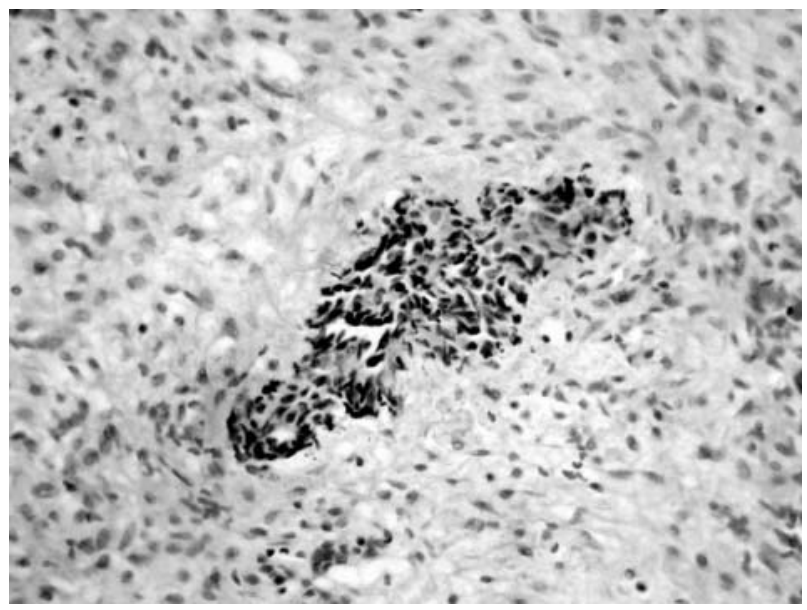

Figure 5 Cohesive group of cells that appears to be within the ovarian stroma.

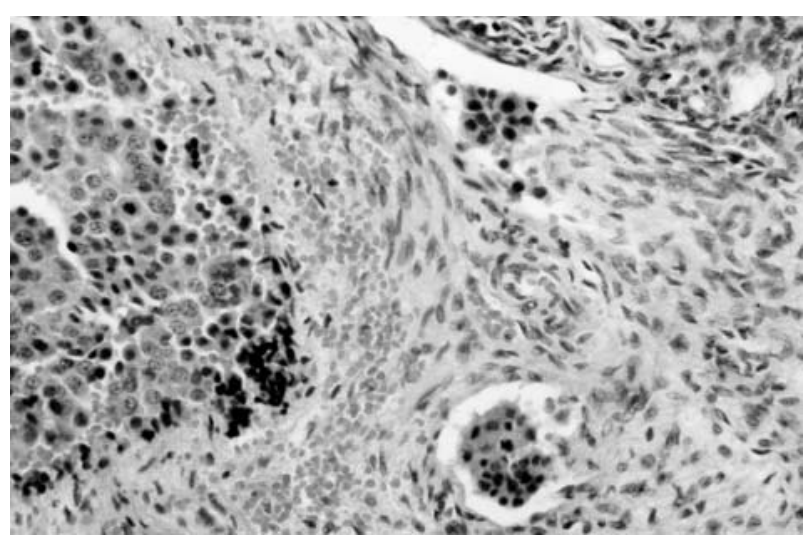

Figure 6 Cohesive cells within a vascular channel adjacent to a follicle lined by granulosa cells.

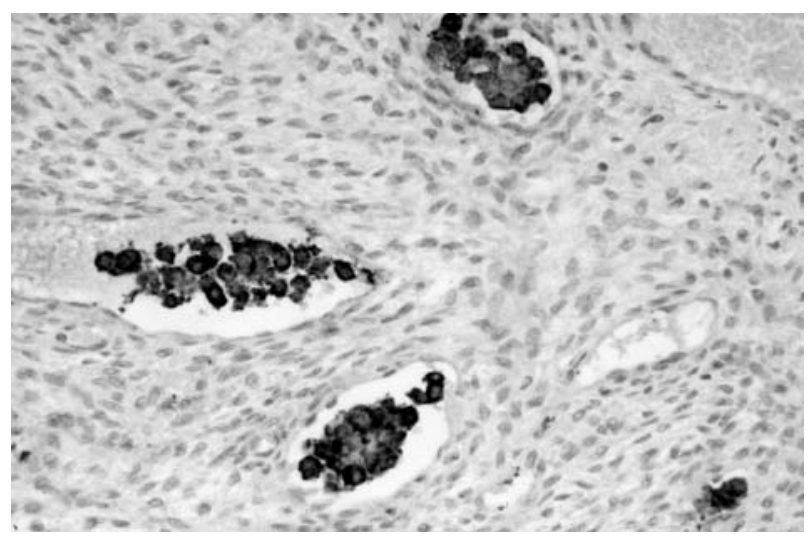

Figure 7 Positive immunohistochemical staining for $\alpha$ inhibin.

immunohistochemistry. Benign granulosa cells, like granulosa cell tumours, are generally positive for $\alpha$ inhibin and calretinin and negative for EMA. ${ }^{7-12}$ Some granulosa cell tumours are positive for cytokeratin, often showing a punctate cytoplasmic staining pattern, ${ }^{12-14}$ and in two of our cases the granulosa cells within the vascular channels were cytokeratin positive. Of course, positivity for cytokeratin may heighten the suspicion of metastatic carcinoma. In the single previous report of benign granulosa cells within ovarian vascular channels, positivity with antibodies reactive against sex cord stromal cells, including $\alpha$ inhibin, assisted in confirming the nature of the cells.

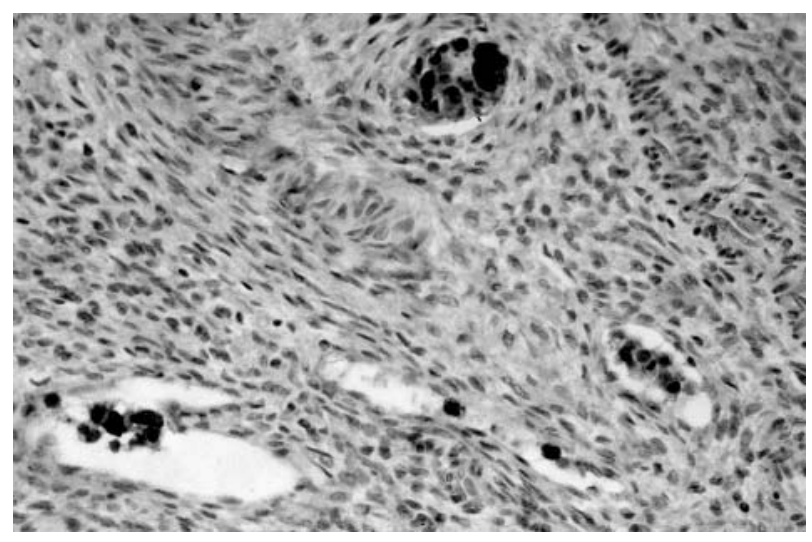

Figure 8 Positive immunohistochemical staining for calretinin. 


\section{Take home messages}

- This report describes six cases characterised by the involvement of ovarian vascular channels by benign granulosa cells, which prompted the pathologists to consider a diagnosis of cancer

- Pathologists should be aware of this rare phenomenon to avoid erroneous diagnoses with subsequent unnecessary investigations

- Such awareness and the lack of other signs of neoplasia should result in the correct interpretation

- The nature of the cells can be confirmed by immunohistochemistry using a panel of antibodies, including those directed against $\alpha$ inhibin, calretinin, and epithelial membrane antigen

- This phenomenon is probably an artefact secondary to surgical trauma or sectioning within the laboratory, or it could be related to ovulation

We believe the occurrence of granulosa cells within vascular channels, and within the ovarian stroma, to be either an artefact related to surgical trauma or cutting of the specimen in the laboratory, or alternatively secondary to ovulation. Granulosa cells, although joined by rudimentary junctions, do not contain well formed desmosomes, ${ }^{15}$ and this may render them especially susceptible to traumatic detachment and incorporation within vascular channels. The crushed nature of the cells in some cases also suggests a traumatic effect.

In summary, we describe a series of cases characterised by involvement of ovarian vascular channels by benign granulosa cells. Pathologists should be aware of this rare phenomenon to avoid erroneous diagnoses with subsequent unnecessary investigations. Awareness of the phenomenon and lack of other evidence of neoplasia will prompt the correct interpretation, and the nature of the cells can be confirmed by immunohistochemistry using a panel of antibodies, including those directed against $\alpha$ inhibin, calretinin, and EMA.

\section{ACKNOWLEDGEMENTS}

We would like to record that Dr R E Scully first drew the attention of one of us (RHY) to this artefactual phenomenon some years ago. We are grateful to Dr Scully for generously allowing us to report the four cases in this report from his files.

\section{Authors' affiliations}

W G McCluggage, Department of Pathology, Royal Group of Hospitals Trust, Belfast

R H Young, James Homer Wright Pathology Laboratories,

Massachusetts General Hospital, Harvard Medical School, Boston, MA, USA

\section{REFERENCES}

1 Scully RE, Young RH, Clement PB. Tumor like lesions. In: Tumors of the ovary, maldeveloped gonads, fallopian tube and broad ligament. Washington: Armed Forces Institute of Pathology, 1998:443-4.

2 Clement PB, Young RH. Tumor-like lesions of the ovary. In: Atlas of gynecologic surgical pathology. Philadelphia: W B Saunders Company 2000:287-8

3 Smith AE, Harmon JP, Deogracias FA, et al. Vascular embolisation of benign granulosa cells. Gynecol Oncol 2000;77:336-8

4 Wu ML, Natarajan S, Lewin KJ. Peculiar artefacts mimicking carcinoma. Arch Pathol Lab Med 2001; 125:1473-6.

5 Douglas-Jones AG, Verghese A. Diagnostic difficulty arising from displaced epithelium after core biopsy in intracystic papillary lesions of the breast. J Clin Pathol 2002;55:780-3.

6 Doglioni C, Dei Tos AP, Laurino L. Calretinin: a novel immunocyłochemical marker for mesothelioma. Am J Surg Pathol 1996;20:1037-46.

7 McCluggage WG. Maxwell P. Immunohistochemical staining for calretinin is useful in the diagnosis of ovarian sex cord-stromal tumours. Histopathology 2001;38:403-8.

8 McCluggage WG. Recent advances in immunohistochemistry in gynaecological pathology. Histopathology 2002;40:309-26.

9 McCluggage WG. The value of inhibin staining in gynecological pathology. Int J Gynecol Pathol 2001;20:79-85.

10 McCluggage WG, Maxwell P, Sloan JM. Immunohistochemical staining of ovarian granulosa cell tumors with monoclonal antibody against inhibin. Hum Pathol 1997; 28:1034-8.

11 Aquirre $\mathbf{P}$, Thor AD, Scully RE. Ovarian endometrioid carcinomas resembling sex cord-stromal tumors: an immunohistochemical study. Int J Gynecol Pathol 1989:8:364-73.

12 Costa MJ, DeRose PB, Rota LM, et al. Immunhistochemical phenotype of ovarian granulosa cell tumors: absence of epithelial membrane antigen has diagnostic value. Hum Pathol 1994;25:60-6.

13 Otis CN, Powell JL, Barbutto D, et al. Intermediate filamentous proteins in adult granulosa cell tumors. Am J Surg Pathol 1992;16:962-8.

14 Czernobilsky B, Moll R, Levy R, et al. Coexpression of cytokeratin and vimentin filaments in mesothelial, granulosa and rete ovarii cells of the human ovary. Eur J Cell Biol 1985;37:175-190.

15 Ferenczy A. The ultrastructural morphology of gynecologic neoplasms. Cancer 1976;38:463-86. 